\title{
Outcome Prediction in Mild Traumatic Brain Injury: Age and Clinical Variables Are Stronger Predictors than CT Abnormalities
}

\author{
Bram Jacobs, ${ }^{1}$ Tjemme Beems, ${ }^{2}$ Maja Stulemeijer, ${ }^{1}$ Arie B. van Vugt, ${ }^{3}$ Ton M. van der Vliet, ${ }^{4}$ \\ George F. Borm, ${ }^{5}$ and Pieter E. Vos ${ }^{1}$
}

\begin{abstract}
Mild traumatic brain injury (mTBI) is a common heterogeneous neurological disorder with a wide range of possible clinical outcomes. Accurate prediction of outcome is desirable for optimal treatment. This study aimed both to identify the demographic, clinical, and computed tomographic (CT) characteristics associated with unfavorable outcome at 6 months after mTBI, and to design a prediction model for application in daily practice. All consecutive mTBI patients (Glasgow Coma Scale [GCS] score: 13-15) admitted to our hospital who were age 16 or older were included during an 8-year period as part of the prospective Radboud University Brain Injury Cohort Study (RUBICS). Outcome was assessed at 6 months post-trauma using the Glasgow Outcome ScaleExtended (GOSE), dichotomized into unfavorable (GOSE score 1-6) and favorable (GOSE score 7-8) outcome groups. The predictive value of several variables was determined using multivariate binary logistic regression analysis. We included 2784 mTBI patients and found CT abnormalities in $20.7 \%$ of the 1999 patients that underwent a head CT. Age, extracranial injuries, and day-of-injury alcohol intoxication proved to be the strongest outcome predictors. The presence of facial fractures and the number of hemorrhagic contusions emerged as CT predictors. Furthermore, we showed that the predictive value of a scheme based on a modified Injury Severity Score (ISS), alcohol intoxication, and age equalled the value of one that also included CT characteristics. In fact, it exceeded one that was based on CT characteristics alone. We conclude that, although valuable for the identification of the individual mTBI patient at risk for deterioration and eventual neurosurgical intervention, CT characteristics are imperfect predictors of outcome after mTBI.
\end{abstract}

Key words: CT-scan; head injury; mild traumatic brain injury; outcome; prediction

\section{Introduction}

$\mathbf{M}$ ILD TRAUMATIC BRAIN INJURY (mTBI) is one of the most common neurological disorders, with an incidence of 100-300/100,000 population (Cassidy et al., 2004). To optimize treatment and for prognostic purposes, knowledge of the demographic, clinical, and radiological parameters related to adverse outcomes are relevant.

Computed tomography (CT) imaging of the brain is the gold standard to detect acute intracranial abnormalities related to head injury. In mTBI, CT is primarily used to identify life-threatening hematomas (extradural, subdural, and intraparenchymal), and other abnormalities including depressed skull fractures, that may require neurosurgical intervention, and further to decide if patients should be admitted, transferred to a neurosurgical center, or discharged (af Geijerstam and Britton, 2005; af Geijerstam et al., 2006; Ingebrigtsen et al., 2000; Smits et al., 2005; Stiell et al., 2001; Vos et al., 2002). The majority of mTBI patients show normal CT scan findings (af Geijerstam and Britton, 2003; Servadei et al., 2001). However, the incidence of $C T$ abnormalities found after mTBI differs considerably among studies, ranging from 3.3$38.8 \%$, depending on the inclusion and exclusion criteria used (Borczuk, 1995; Bordignon and Arruda, 2002; Culotta et al., 1996; Dunham et al., 1996; Gomez et al., 1996; Harad and Kerstein, 1992; Haydel et al., 2000; Hsiang et al., 1997; Ibanez et al., 2004; Iverson et al., 2000; Jeret et al., 1993; Livingston et al., 2000; Miller et al., 1996; Miller et al., 1997; Moran et al., 1994; Nagy et al., 1999; Sadowski-Cron et al., 2006; Shackford et al., 1992; Smits et al., 2005; Stein and Ross, 1990, 1992; Stiell

\footnotetext{
${ }^{1}$ Department of Neurology, ${ }^{2}$ Department of Neurosurgery, ${ }^{3}$ Department of Emergency Medicine, ${ }^{4}$ Department of Radiology, and ${ }^{5}$ Department of Epidemiology, Biostatistics and HTA, Radboud University Nijmegen Medical Centre (RUNMC), Nijmegen, the Netherlands.
} 
et al., 2001, 2005; Styrke et al., 2007; Thiruppathy and Muthukumar, 2004; Viola et al., 2000). In a selected group of patients with clinical signs of skull (base) fractures the percentage of intracranial abnormalities found on head CT may reach $70.2 \%$ (de Andrade et al., 2006). The value of CT in identifying acute life-threatening hematomas in individual patients has been clearly established. For this reason exploration of the association between $\mathrm{CT}$ abnormalities and the long-term effects of mTBI seems reasonable. However, the search for CT predictors of long-term outcome after mTBI has yielded conflicting results thus far. Both a positive correlation (Hsiang et al., 1997; Kido et al., 1992; Perel et al., 2008; Sadowski-Cron et al., 2006; Signorini et al., 1999; Smits et al., 2008; van der Naalt et al., 1999a; Wallesch et al., 2001; Wardlaw et al., 2002), and an absence of correlation (McCullagh et al., 2001; Stulemeijer et al., 2007) between the presence of intracranial abnormalities on CT and 6- to 12month outcome have been found. The primary outcome measures in these studies differed considerably, and varied from death/survival to cognitive functioning and the presence of post-traumatic complaints. Furthermore, the CT characteristics that have surfaced as predictors of adverse outcome differ per study. Traumatic subarachnoid hemorrhage (Wardlaw et al., 2002), edema (van der Naalt et al., 1999a), the presence of focal lesions (van der Naalt et al., 1999a; Wallesch et al., 2001), visible hematomas (Signorini et al., 1999), signs of diffuse axonal injury, signs of parenchymal damage (Smits et al., 2008), and the size of focal lesions (Kido et al., 1992), all have been identified as outcome predictors. Finally, the mere presence of acute CT abnormalities (Hsiang et al., 1997; Sadowski-Cron et al., 2006), and the overall CT appearance (Wardlaw et al., 2002), have also been suggested to be associated with functional outcome. Unfortunately, it is difficult to draw solid conclusions from these studies of the predictive value of CT for mTBI outcomes, because CT predictors were not compared with clinical and demographic factors (Smits et al., 2008; van der Naalt et al., 1999a), the studies used relatively small sample sizes (Kido et al., 1992; van der Naalt et al., 1999a; Wallesch et al., 2001), or data were only analyzed in a univariate way (McCullagh et al., 2001; Sadowski-Cron et al., 2006; Wallesch et al., 2001). In addition, $\mathrm{mTBI}$ patients were combined with more severely brain-injured patients (Kido et al., 1992; Signorini et al., 1999; van der Naalt et al., 1999a; Wallesch et al., 2001; Wardlaw et al., 2002). This may mistakenly result in concluding that CT variables are predictive of outcome for all TBI severities, though the actual predictive value of the CT abnormalities is based on their predictive power in the most severely affected patients.

In contrast, studies investigating clinical and demographic predictors of outcome, but excluding radiological characteristics, emphasize the predictive ability of the Glasgow Coma Scale (GCS), post-traumatic amnesia (PTA), initial complaints (headache, nausea, and dizziness), age, and gender for mTBI (Carroll et al., 2004; van der Naalt, 2001). Whereas hypoxia and hypotension are strong predictors in moderate and severe TBI (Hukkelhoven et al., 2005), they have not emerged as outcome predictors in mTBI (Carroll et al., 2004). In a multiple regression analysis PTA, but not GCS score at hospital admission, predicted outcome as assessed with the Glasgow Outcome Scale (GOS) (van der Naalt et al., 1999b). This predictive value of PTA, however, was not confirmed by others
(McCullagh et al., 2001; Ponsford et al., 2000). Additional extracranial injuries such as long bone or pelvic fractures may prolong the rehabilitation period and are independent outcome predictors in mTBI (Signorini et al., 1999; Stulemeijer et al., 2006, 2007). Furthermore, it has been consistently shown that acute post-traumatic complaints (e.g., dizziness, headache, or vomiting) in the ED predict post-traumatic complaints at 1-6 months post-injury (Chamelian and Feinstein, 2004; de Kruijk et al., 2002; Savola and Hillbom, 2003; Stulemeijer et al., 2007). Interestingly, GCS score had only a very modest predictive capacity in a number of studies (McCullagh et al., 2001; Stulemeijer et al., 2007; van der Naalt et al., 1999b). Finally, using multivariate analysis, results of a large prospective study demonstrated the predictive value of age, pre-existing physical limitations, and a history of brain illness (Thornhill et al., 2000); however, the variance in outcomes in this study was low.

A recent large international multicenter study investigated the predictive value of demographic, clinical, and CT characteristics multivariately in patients suffering from mild (GCS score 13-14), moderate (GCS score 9-12), or severe (GCS score $\leq 8)$ TBI (Perel et al., 2008). The GCS score, pupil reactivity, major extracranial injury, age, and several CT characteristics (compression of the basal cisterns and third ventricle, subarachnoid hemorrhage [SAH], midline shift, and presence of a non-evacuated hematoma) were the strongest independent predictors of unfavorable outcome at 6 months post-injury. However, it is not possible to use these factors in the modeling of mTBI outcome prediction because no subdivision was made by injury severity.

Only a few studies have compared the relative predictive ability of CT characteristics with demographic and acute clinical variables in a multivariate analysis (Hsiang et al., 1997; Signorini et al., 1999; Stulemeijer et al., 2007; Wardlaw et al., 2002). The presence of acute CT abnormalities was associated with an increasingly worse 6-month outcome with decreasing GCS score (Hsiang et al., 1997). In two studies, both including more severely-injured TBI patients, the presence of a traumatic hematoma (Signorini et al., 1999), and a combination of traumatic SAH and poor overall CT appearance (Wardlaw et al., 2002) were independent predictors when age, GCS score, and pupil reactivity were also entered into the prediction models. In a recent study $\mathrm{CT}$ abnormalities did not improve outcome prediction in mTBI when the patient's education, subacute post-traumatic symptoms (nausea, vomiting, and pain), and concurrently sustained extracranial injuries were included (Stulemeijer et al., 2007).

In this study we aim to gain insight into the composition and frequency of several demographic, clinical, and CT variables of mTBI. To identify the predictors of functional outcome after mTBI, we compared CT characteristics with demographic and clinical variables in a prospective cohort of consecutive patients. After multivariate analysis, predictive models were designed that may be useful in daily clinical practice.

\section{Methods}

\section{Subjects}

All patients with mTBI aged 16 and older admitted to the emergency department (ED) of the Radboud University Nijmegen Medical Centre (RUNMC), a level I trauma center with 
a referral area of 2.5 million inhabitants, between January 1998 and January 2006, were eligible for inclusion. MTBI was defined as an acute insult to the brain caused by an external physical force, and an ED GCS score of 13-15 after initial resuscitation, or a GCS score of 13-15 at admission before sedation and intubation during resuscitation for a nonneurological cause. Patients suffering from penetrating head injury, defined as head injury caused by penetration of a foreign body like a knife or bullet, were excluded. Polytrauma patients with significant extracranial injury (Injury Severity Score [ISS] $\geq 16$ ) were not excluded.

The data for this study were obtained from the Radboud University Brain Injury Cohort Study (RUBICS). RUBICS is an ongoing prospective observational cohort study that started January 1, 1998. All consecutive patients, including children, admitted to the ED of the RUNMC with a diagnosis of mild, moderate, or severe TBI are included. Patients are registered in the RUBICS database when according to the hospital protocol, a neurologist and/or neurosurgeon is consulted in the ED when a head trauma patient is presented with: (1) a GCS score of 3-14; or (2) a GCS score of 15 with loss of consciousness (LOC) and/or PTA; or (3) a GCS score of 15 without LOC or PTA, but fulfilling additional criteria according to the guidelines proposed by the European Federation of Neurological Societies (EFNS), which include unclear or ambiguous accident history; persistent or progressive headache, nausea, and vomiting; intoxication with alcohol or drugs; epileptic seizure; coagulation disorders; use of platelet aggregation inhibitors or oral anticoagulation; confusion, retrograde amnesia, or focal neurological deficits; age $>60$ and $<2$ years; high-energy accident; or visible trauma above the clavicles (including signs of skull or skullbase fracture) (Vos et al., 2002). Recently it was shown that the EFNS guidelines have $100 \%$ sensitivity for the identification of neurocranial complications after minor head injury (Smits et al., 2007a). Using these guidelines all mTBI patients would be included in the RUBICS database, which is also in accordance with the criteria of the mTBI Committee of the Head Injury Interdisciplinary Special Interest Group of the American Congress of Rehabilitation Medicine (Kay et al., 1993).

The RUBICS database comprises demographic data (age and gender), clinical and radiological injury variables, and outcome scores. Injury characteristics recorded for this study include: injury type, presence of hypotension (systolic BP $<90 \mathrm{~mm} \mathrm{Hg}$, equal to shock class III-IV [American College of Surgeons, 2004]), and hypoxia (oxygen saturation $<90 \%$ as measured by pulse oximetry), during the prehospital period or at the ED. Further, the Abbreviated Injury Scale of the Head (AISH) score, ISS score (Baker et al., 1974), GCS score, pupil responses, presence and duration of coma, and PTA were also recorded. The presence and duration of both LOC and PTA were based on witness and paramedic reports when available. In the ED, the presence of amnesia and ongoing PTA were determined by emergency physicians and neurological consultants using a PTA questionnaire. When information regarding the pre-hospital presence of LOC and PTA was ambiguous this was recorded as such, but for statistical analysis these cases were added to the "absent" category. Finally, we recorded a clinical suspicion of day-of-injury alcohol intoxication or definite day-of-injury intoxication when the blood alcohol level exceeded $\geq 100 \mathrm{mg} / \mathrm{L}$, and the use of oral anticoagulants. Additionally, several CT characteristics and the Trauma Coma Databank (TCDB) CT classification were recorded (Marshall et al., 1991). To quantify additional extracranial injuries, an alternative modified ISS score was calculated based on the three most severely injured body areas excluding the head, as the ISS-extracranial score (ISSe). Patients were categorized as having isolated mTBI (versus polytrauma) when they sustained a mild TBI without any substantial additional injury, defined by an AIS score $<2$ in one of the AIS-ISS body regions. Patients were assessed by neurologists (residents) and/or neurosurgeons (residents) according to hospital protocol, and data were recorded as such, after which all clinical data were collected by a trained research nurse as soon as possible post-injury, generally on the day of injury, and recorded on forms before entry into our digital database.

\section{Outcome assessment}

Outcome was assessed at 6 months post-injury according to the Glasgow Outcome Score-Extended (GOSE), using a structured interview during regular visits to the outpatient clinic or during consultation by telephone (Wilson et al., 1998). In short, the GOSE is an 8-point scale expressing functional outcome, ranging from $1=$ death, to $8=$ complete recovery. GOSE score 2 represents a vegetative state, GOSE score 3 indicates 24-h dependency (at home), GOSE 4 score means that the patient is dependent but can do without help for at least eight consecutive hours, GOSE score 5 denotes independence in activities of daily living but no resumption of former employment, GOSE score 6 means reduced capacity for work, and GOSE score 7 indicates resumption of former employment, but with persistent complaints that interfere with activities of daily living (Wilson et al., 1998). A GOSE score of 6 or lower was considered as an unfavorable outcome in this study and was dichotomized as such for statistical purposes. Patients not visiting the outpatient clinic were sent a GOSE questionnaire by regular mail, and if not returned a reminder was sent (Wilson et al., 2002). Finally, we attempted to reach all non-responding patients by telephone. If no outcome was obtained directly from the patient, charts and correspondence were reviewed to determine outcome and construct a GOSE score using the structured interview (Wilson et al., 1998) as a guideline. Because retrospective determination of outcome based on chart review rather than a formal personal interview may be considered artificial and susceptible to errors, several analyses were also carried out without inclusion of these patients. Outcomes determined within 3 months were also accepted if no outcome at 6 months was available. When the patient had a GOSE score of 7 or 8 by 4.5 months post-injury, it was considered a definitive outcome. Patients with no outcome score or an outcome score that did not meet the above criteria were considered lost to follow-up.

\section{Computed tomography}

Patients were scheduled to undergo a CT scan of the head according to EFNS guidelines (Vos et al., 2002). Only the initial CT scans of patients admitted to the hospital within $72 \mathrm{~h}$ after sustaining head injury were used in this study. Each CT scan was scored as soon as possible post-injury by one of three raters (B.J., T.B. and P.E.V.) using a predefined format (see below). In addition, all scans were classified according to the 
TCDB CT classification (Marshall et al., 1991). Using a structured format the following CT characteristics were recorded on data entry sheets:

- The status (presence, compression, or absence) of the ventricular system and the cisterns

- The presence, location, type, number, and size of any low-, mixed-, or high-density lesions, including subdural hematomas (SDH), epidural hematomas (EDH), intraparenchymal hematomas, and hemorrhagic contusions; intraparenchymal hematomas and hemorrhagic contusions were combined into one category, hemorrhagic contusions; where applicable the volume of space-occupying lesions was calculated as previously described (Pasqualin et al., 1991; Vos et al., 2001)

- The presence and type of subarachnoid and intraventricular hemorrhage

- The presence and location (subcortical, basal ganglia/corpus callosum, or brainstem) of punctate hemorrhages (diameter $\leq 5 \mathrm{~mm}$ )

- The presence and location of edema (focal or diffuse)

- The presence and quantity of midline shift

- The presence of pneumocephalus

- The presence and type of facial, vault, or skullbase fractures

- The presence of extracranial hematomas

\section{Statistical analysis}

To detect significant differences between the patients included in the outcome analysis and the patients lost to followup, the Student's $t$-test, chi-square test, and non-parametric variants were used where applicable. We used binary logistic regression analysis to identify the demographic, clinical, and CT characteristics associated with unfavorable outcome after mTBI. Missing data were excluded from the analysis. As dependent variables we dichotomized the 6-month outcome as favorable (GOSE score 7 or 8), or unfavorable (GOSE score 1-6). Initially all demographic, clinical, and CT characteristics, were tested univariately. Age was analyzed per year, and GCS, AISH, ISS, and ISSe scores were all analyzed numerically. The other clinical variables were binary (presence versus absence). With regard to the $\mathrm{CT}$ parameters, midline shift was analyzed per millimeter, the volume of the lesions per milliliter, and the number of hematomas/contusions was assessed. The remaining variables were nominal: 'largest lesion,' ordinal: 'presence of lesions,' or dichotomous categorical variables. The clinical variables were analyzed for the entire mTBI group, and CT characteristics were analyzed only in patients in whom a CT of the head was performed.

Possible predictors of unfavorable outcome at 6 months post-mTBI were analyzed multivariately, using the forward stepwise likelihood ratio method. The clinical and demographic variables were combined, as were the CT variables. Besides a multivariate analysis including the ISS, a combination of AISH and ISSe replacing the ISS was included as an analogue multivariate analysis. In addition, by using the independent predictive variables, three prediction rules were designed to enable the utilization of these predictors in daily clinical practice: one "clinical rule," comprising demographic and clinical variables, and one "CT rule," comprising CT parameters. The independent demographic, clinical, and CT predictors were combined, and their predictive value was subsequently used to design the third "combination" rule. The three prediction models were analyzed for their sensitivity and specificity in predicting unfavorable outcome using receiver operating characteristic (ROC) analysis, quantified by the area under the receiver operating curve (AUC). This is a measure of predictive discrimination, in which a score of 0.50 $(50 \%)$ is equivalent to random guessing, and a score of 1.00 $(100 \%)$ is perfect prediction. The higher the AUC, the higher the sensitivity and specificity (i.e., the ability to correctly predict outcome).

Previously we demonstrated a strong relationship between extracranial injuries and outcome after mTBI (Stulemeijer et al., 2006). Therefore, we also explored the predictive value of all variables in isolated mTBI using the same procedures as those described above.

Throughout we used a two-sided $p$ value of 0.01 as the criterion for significance, except for the AUC (for which we used $p<0.05$ ). We chose 0.01 in order to avoid irrelevant findings of statistical significance due to the large number of variables involved.

\section{Results}

Figure 1 shows the inclusion and exclusion criteria and the total numbers of patients considered for the study. The demographic and clinical characteristics at presentation were evaluated in 2784 patients, the CT characteristics were evaluated in 1999 patients, and for the outcome prediction 1069 patients were analyzed. In $53(5.0 \%)$ of these patients the GOSE scores were determined based on outcome information from the patients' charts.

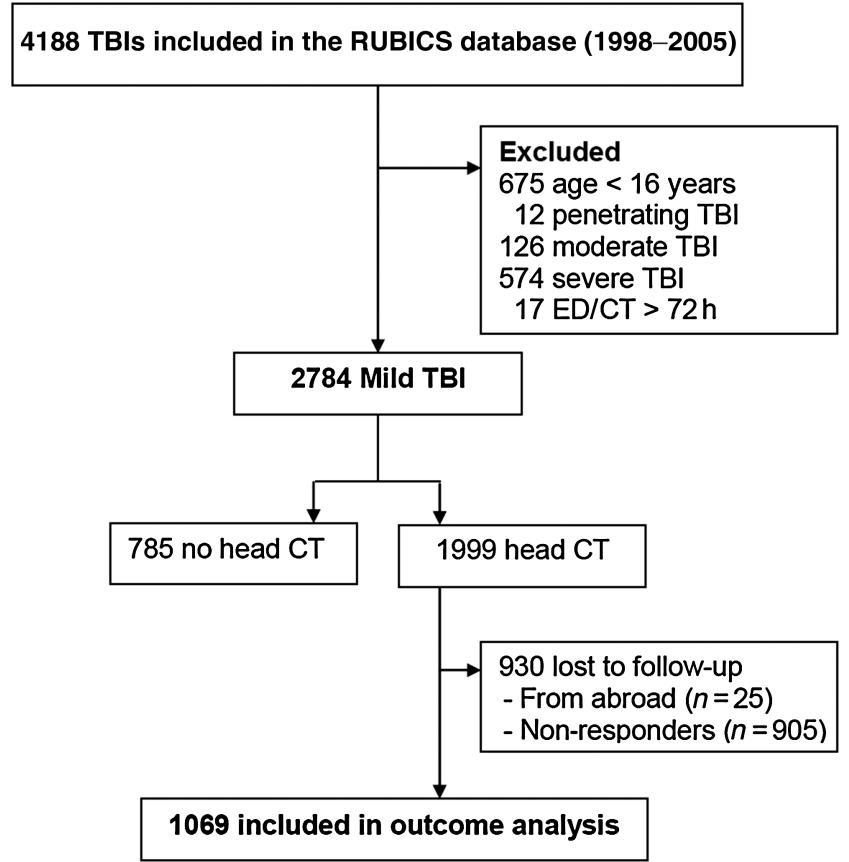

FIG. 1. Diagram showing the inclusion and exclusion criteria of the patients in this study (RUBICS, Radboud University Nijmegen Brain Injury Cohort Study; TBI, traumatic brain injury; ED, emergency department; CT, computed tomography). 
Table 1. Patient Demographic and Clinical Characteristics at Presentation

\begin{tabular}{|c|c|c|c|c|c|}
\hline Variable & $\begin{array}{c}\text { A: mTBI total } \\
(\mathrm{n}=2784)\end{array}$ & $\begin{array}{c}\text { B: CT-positive } \\
(\mathrm{n}=1999)\end{array}$ & $\begin{array}{c}\text { C: CT-positive and } \\
\text { GOSE-positive } \\
(\mathrm{n}=1069)\end{array}$ & $\begin{array}{c}\text { D: CT-positive and } \\
\text { GOSE-negative } \\
(\mathrm{n}=930)\end{array}$ & $\begin{array}{c}\text { Difference } \\
\text { between } C \text { and } D\end{array}$ \\
\hline Male gender & $1823(66 \%)$ & $1351(68 \%)$ & $695(65 \%)$ & $656(71 \%)$ & $p=0.008$ \\
\hline $\operatorname{Age}^{\mathrm{a}}$ & $41.2(19.0)$ & $42.7(19.3)$ & $42.4(18.5)$ & $43.0(20.3)$ & n.s. \\
\hline \multicolumn{6}{|l|}{ Trauma mechanism } \\
\hline Traffic & $1534(55 \%)$ & $1092(55 \%)$ & $615(58 \%)$ & 477 (51\%) & $p<0.0001$ \\
\hline Fall & $793(29 \%)$ & $591(30 \%)$ & $304(28 \%)$ & $287(31 \%)$ & \\
\hline Sports & $160(6 \%)$ & $109(6 \%)$ & $64(6 \%)$ & $45(5 \%)$ & \\
\hline Violence & $231(8 \%)$ & $165(8 \%)$ & $64(6 \%)$ & $101(11 \%)$ & \\
\hline Suicide & $20(1 \%)$ & $12(1 \%)$ & $6(1 \%)$ & $6(1 \%)$ & \\
\hline Other/missing & $46(2 \%)$ & $30(2 \%)$ & $16(2 \%)$ & $14(2 \%)$ & \\
\hline GCS score at ED 13 & $130(5 \%)$ & $118(6 \%)$ & $81(8 \%)$ & $37(4 \%)$ & $p<0.0001$ \\
\hline GCS score at ED 14 & $342(12 \%)$ & $318(16 \%)$ & $189(18 \%)$ & $129(14 \%)$ & \\
\hline GCS score at ED 15 & $2312(83 \%)$ & $1563(78 \%)$ & $799(75 \%)$ & $764(82 \%)$ & \\
\hline $\mathrm{AISH}^{\mathrm{a}}$ & $2.1(0.8)$ & $2.2(0.8)$ & $2.3(0.9)$ & $2.0(0.7)$ & $p<0.0001$ \\
\hline ISS $^{\mathrm{a}}$ & $8.7(7.4)$ & $9.1(7.6)$ & $10.0(8.1)$ & $8.1(6.8)$ & $p<0.0001$ \\
\hline Hypotensive episode & $34(1 \%)$ & $33(2 \%)$ & $20(2 \%)$ & $13(1 \%)$ & n.s. \\
\hline Hypoxic episode & $33(1 \%)$ & $33(2 \%)$ & $22(2 \%)$ & $11(1 \%)$ & n.s. \\
\hline At least one non-reactive pupil & $28(1 \%)$ & $26(1 \%)$ & $18(2 \%)$ & $8(1 \%)$ & n.s. \\
\hline Ethanol intoxication & $766(28 \%)$ & $607(30 \%)$ & $275(27 \%)$ & $332(36 \%)$ & $p<0.0001$ \\
\hline Ethanol (\%o) at ED ${ }^{\mathrm{a}}$ & $2.1(0.9)$ & $2.2(0.9)$ & $2.1(0.9)$ & $2.2(1.0)$ & n.s. \\
\hline Presence of PTA & $1511(54 \%)$ & $1228(61 \%)$ & $712(67 \%)$ & $516(56 \%)$ & $p<0.0001$ \\
\hline PTA duration (min) ${ }^{b}$ & 15 & 30 & 30 & 15 & n.s. \\
\hline Presence of LOC & $1060(38 \%)$ & $811(41 \%)$ & $460(43 \%)$ & $351(38 \%)$ & $p=0.039$ \\
\hline LOC duration $(\mathrm{min})^{\mathrm{b}}$ & 5 & 5 & 5 & 5 & n.s. \\
\hline Use of anticoagulants & $117(4 \%)$ & $104(5 \%)$ & $54(5 \%)$ & $50(5 \%)$ & n.s. \\
\hline Neurosurgical intervention & $19(1 \%)$ & $19(1 \%)$ & $16(2 \%)$ & $3(0.3 \%)$ & $p=0.007$ \\
\hline Outcome $(\mathrm{n}=1226)$ & & $(n=1069)$ & & & \\
\hline Death (GOSE score 1) & $40(3 \%)$ & $38(2 \%)$ & $38(4 \%)$ & & \\
\hline Unfavorable (GOSE score 1-6) & $285(23 \%)$ & $257(13 \%)$ & $257(24 \%)$ & & \\
\hline
\end{tabular}

${ }^{\mathrm{a}}$ Mean (SD), ${ }^{\mathrm{b}}$ median; all other variables: $n$ and (\%).

mTBI, mild traumatic brain injury; GCS, Glasgow Coma Scale; ED, emergency department; AISH, Abbreviated Injury Scale of the Head; ISS, Injury Severity Score; GOSE, Glasgow Outcome Scale-Extended; SD, standard deviation; PTA, post-traumatic amnesia; LOC, loss of consciousness; n.s., not significant.

Demographic and clinical characteristics of all included patients, and the patients eventually used in the outcome analysis, are shown in Table 1.

We focused our analysis on the patients that underwent a head CT. In this group demographic and clinical data were missing in less than $1.5 \%$, except for the presence of alcohol intoxication $(3 \% ; n=61)$. The presence of PTA was uncertain in 261 patients $(9.4 \%)$, and LOC in $694(24.9 \%)$ patients. Our study participants were predominantly male $(68 \%)$ with a mean age of 42.7 years. The leading causes of trauma were traffic accidents $(55 \%)$ and falls (30\%). The majority of patients experienced mild trauma, as represented by the low mean ISS score of 9.1. In $19(0.7 \%)$ patients neurosurgical intervention was necessary. Seven patients were operated on for EDH (one in combination with compression fracture), seven patients were operated on for SDH, three patients for a hemorrhagic contusion (one in combination with a compression fracture), and two patients for a combination of an EDH and a SDH. A total of $38(2 \%)$ patients died, and $257(13 \%)$ mTBI patients had an unfavorable outcome (GOSE score 1-6). Although the differences were small, the patients included in the outcome prediction analyses differed significantly from the patients lost to follow-up, with regard to gender, trauma mechanism, GCS at the ED, AISH score, ISS score, day-of-injury alcohol intoxication, presence of PTA (for duration of PTA they did not differ significantly), and neurosurgical intervention. Thus they had a more severe injury profile. The distribution of major CT characteristics, including the patient distribution over the different categories of the TCDB CT classification, is presented in Table 2.

For all CT characteristics fewer than $0.5 \%$ of the required values were missing. Intracranial abnormalities were found in $389(19.5 \%)$ patients. When vault and skullbase fractures were included, abnormalities were present in 414 (20.7\%) patients. Edema was the most frequent intracranial abnormality (239; $12 \%$ ), with an inter-rater agreement (B.J. and P.E.V.) of $82 \%$. Isolated edema, focal or diffuse, without any other intracranial abnormality was seen in $63(3 \%)$ patients. In 186 patients (9\%) one or more lesions, excluding punctate hemorrhages, were present; in 40 patients (2\%) an EDH was the dominant lesion, in 50 patients (3\%) an SDH was the dominant lesion, and in 95 patients $(5 \%)$ a hemorrhagic contusion was the dominant lesion. Of all lesions, 40 had a volume of $25 \mathrm{~mL}$ or more. The mean volume of the largest lesion per patient was $21.0 \mathrm{~mL}$ (median: $6.8 \mathrm{~mL}$ ). Traumatic $\mathrm{SAH}$ was demonstrated in 115 patients $(6 \%)$, and 67 patients $(3 \%)$ showed evidence of abnormal basal cisterns. Finally, in 52 patients (3\%) there was a midline shift (mean $4.6 \mathrm{~mm}$; median $3.9 \mathrm{~mm}$ ). Subdivided by GCS score, intracranial abnormalities were found in $16 \%$ of patients with a GCS score of $15,27 \%$ of patients with a GCS 
TABle 2. CT Characteristics of the 1999 mTBI Patients InCluded in the RUBICS Database (1998-2005)

\begin{tabular}{|c|c|c|c|c|}
\hline CT characteristic & $\begin{array}{c}A: \text { mTBI patients } \\
\quad(\mathrm{n}=1999)\end{array}$ & $\begin{array}{c}\text { B: GOSE-positive } \\
(\mathrm{n}=1069)\end{array}$ & $\begin{array}{c}\text { C: GOSE-negative } \\
(\mathrm{n}=930)\end{array}$ & $\begin{array}{c}\text { Difference } \\
\text { between } B \text { and } C\end{array}$ \\
\hline Intracranial abnormalities & $389(20 \%)$ & $281(26 \%)$ & $108(12 \%)$ & $p<0.0001$ \\
\hline GCS score 13 & $54(46 \%)$ & $45(56 \%)$ & $9(24 \%)$ & \\
\hline GCS score 14 & $84(27 \%)$ & $62(33 \%)$ & $22(17 \%)$ & \\
\hline GCS score 15 & $251(16 \%)$ & $174(22 \%)$ & $77(10 \%)$ & \\
\hline Intracranial abnormalities and fractures & $414(21 \%)$ & $299(28 \%)$ & $115(12 \%)$ & $p<0.0001$ \\
\hline \multicolumn{4}{|l|}{ TCDB-classification } & $p<0.0001$ \\
\hline Diffuse injury I & $1607(80 \%)$ & $786(74 \%)$ & $821(88 \%)$ & \\
\hline Diffuse injury II & $311(16 \%)$ & $217(20 \%)$ & $94(10 \%)$ & \\
\hline Diffuse injury III & $30(2 \%)$ & $24(2 \%)$ & $6(1 \%)$ & \\
\hline Diffuse injury IV & $1(0.1 \%)$ & $1(0.1 \%)$ & & \\
\hline $\begin{array}{l}\text { Evacuated mass lesion or neurosurgical } \\
\text { intervention }\end{array}$ & $19(1 \%)$ & $16(2 \%)$ & $3(0.3 \%)$ & \\
\hline Non-evacuated mass lesion & $28(1.4 \%)$ & $23(2 \%)$ & $5(1 \%)$ & \\
\hline Missing & $3(0.1 \%)$ & $2(0.2 \%)$ & $1(0.1 \%)$ & \\
\hline \multicolumn{4}{|l|}{ Foramen magnum } & $p=0.038$ \\
\hline Normal & 1987 (99\%) & $1059(99 \%)$ & $928(99.8 \%)$ & \\
\hline Abnormal & $12(1 \%)$ & $10(1 \%)$ & $2(0.2 \%)$ & \\
\hline Missing & & & & \\
\hline \multicolumn{4}{|l|}{ Basal cisterns } & $p<0.0001$ \\
\hline Normal & $1932(97 \%)$ & $1013(96 \%)$ & $919(99 \%)$ & \\
\hline Abnormal & $67(3 \%)$ & $56(5 \%)$ & $11(1 \%)$ & \\
\hline \multicolumn{5}{|l|}{ Missing } \\
\hline No lesion & $1809(91 \%)$ & $919(86 \%)$ & $890(96 \%)$ & $p<0.0001$ \\
\hline One lesion & $130(7 \%)$ & $98(9 \%)$ & $32(3 \%)$ & \\
\hline Multiple lesions & $56(3 \%)$ & $49(5 \%)$ & $7(1 \%)$ & \\
\hline Missing & $4(0.2 \%)$ & $3(0.3 \%)$ & $1(0.1 \%)$ & \\
\hline \multicolumn{4}{|l|}{ Dominant (largest) lesion } & $p<0.0001$ \\
\hline $\mathrm{EDH}$ & $40(2 \%)$ & $32(3 \%)$ & $8(1 \%)$ & \\
\hline $\mathrm{SDH}$ & $50(3 \%)$ & $41(4 \%)$ & $9(1 \%)$ & \\
\hline Hemorrhagic contusion & $95(5 \%)$ & $73(7 \%)$ & $22(2 \%)$ & \\
\hline Missing & $5(0.3 \%)$ & $4(0.4 \%)$ & $1(0.1 \%)$ & \\
\hline Volume of dominant lesion $(m L)^{\mathrm{a}}$ & $21.0(39.2)$ & $21.4(40.0)$ & $19.6(36.0)$ & n.s. \\
\hline EDH present & $49(3 \%)$ & $40(4 \%)$ & $9(1 \%)$ & $p<0.0001$ \\
\hline SDH present & $69(4 \%)$ & $56(5 \%)$ & $13(1 \%)$ & $p<0.0001$ \\
\hline Hemorrhagic contusion present & $116(6 \%)$ & $92(9 \%)$ & $24(3 \%)$ & $p<0.0001$ \\
\hline \multicolumn{5}{|l|}{ Total number of lesions } \\
\hline $\mathrm{EDH}$ & 49 & 40 & 9 & $p<0.0001$ \\
\hline $\mathrm{SDH}$ & 77 & 61 & 16 & $p<0.0001$ \\
\hline Hemorrhagic contusion & 142 & 112 & 30 & $p<0.0001$ \\
\hline Missing & 2 & 2 & 0 & \\
\hline \multirow{5}{*}{$\begin{array}{l}\text { SAH } \\
\text { Focal, thickness }<1 \mathrm{~mm} \\
\text { Focal, thickness }>1 \mathrm{~mm} \\
\text { Diffuse/intraventricular } \\
\text { Missing }\end{array}$} & $115(6 \%)$ & $83(8 \%)$ & $32(3 \%)$ & $p<0.0001$ \\
\hline & $72(4 \%)$ & $54(5 \%)$ & $18(2 \%)$ & $p<0.0001$ \\
\hline & $24(1 \%)$ & $15(1 \%)$ & $9(1 \%)$ & \\
\hline & $19(1 \%)$ & $14(1 \%)$ & $5(1 \%)$ & \\
\hline & $4(0.2 \%)$ & $3(0.3 \%)$ & $1(0.1 \%)$ & \\
\hline \multirow{5}{*}{$\begin{array}{l}\text { Petechial hemorrhage } \\
\text { Subcortical } \\
\text { Basal ganglia } \\
\text { Brainstem } \\
\text { Missing }\end{array}$} & $75(4 \%)$ & $52(5 \%)$ & $23(3 \%)$ & $p=0.009$ \\
\hline & $69(4 \%)$ & $49(5 \%)$ & $20(2 \%)$ & $p=0.005$ \\
\hline & $6(0.3 \%)$ & $5(1 \%)$ & $1(0.1 \%)$ & \\
\hline & $3(0.2 \%)$ & $1(0.1 \%)$ & $2(0.2 \%)$ & \\
\hline & $4(0.2 \%)$ & $3(0.3 \%)$ & $1(0.1 \%)$ & \\
\hline \multirow{4}{*}{$\begin{array}{l}\text { Edema } \\
\text { Focal } \\
\text { Diffuse } \\
\text { Missing }\end{array}$} & $239(12 \%)$ & $174(16 \%)$ & $65(7 \%)$ & $p<0.0001$ \\
\hline & $197(10 \%)$ & $143(13 \%)$ & $54(6 \%)$ & $p<0.0001$ \\
\hline & $42(2 \%)$ & $31(3 \%)$ & $11(1 \%)$ & \\
\hline & $4(0.2 \%)$ & $4(0.4 \%)$ & $1(0.1 \%)$ & \\
\hline \multirow{4}{*}{$\begin{array}{l}\text { Vault fracture } \\
\text { Linear } \\
\text { Compression } \\
\text { Missing }\end{array}$} & $69(4 \%)$ & $56(5 \%)$ & $13(1 \%)$ & $p<0.0001$ \\
\hline & $63(3 \%)$ & $52(5 \%)$ & $10(1 \%)$ & $p<0.0001$ \\
\hline & $6(0.3 \%)$ & $3(0.3 \%)$ & $3(0.4 \%)$ & \\
\hline & $4(0.2 \%)$ & $3(0.3 \%)$ & $1(0.1 \%)$ & \\
\hline
\end{tabular}


TABle 2. Continued

\begin{tabular}{lcccc}
\hline CT characteristic & $\begin{array}{c}\text { A: mTBI patients } \\
(\mathrm{n}=1999)\end{array}$ & $\begin{array}{c}\text { B: GOSE-positive } \\
(\mathrm{n}=1069)\end{array}$ & $\begin{array}{c}\text { C: GOSE-negative } \\
(\mathrm{n}=930)\end{array}$ & $\begin{array}{c}\text { Difference } \\
\text { between B and C }\end{array}$ \\
\hline Skullbase fracture & $71(4 \%)$ & $60(6 \%)$ & $11(1 \%)$ & $p<0.0001$ \\
Missing & $4(0.2 \%)$ & $3(0.3 \%)$ & $1(0.1 \%)$ & \\
Pneumocephalus & $59(3 \%)$ & $50(5 \%)$ & $9(1 \%)$ & \\
Missing & $5(0.3 \%)$ & $4(0.4 \%)$ & $1(0.1 \%)$ & \\
Facial fracture & $303(15 \%)$ & $184(17 \%)$ & $119(13 \%)$ & \\
Missing & $4(0.2 \%)$ & $3(0.3 \%)$ & $1(0.1 \%)$ & \\
Midline shift & $52(3 \%)$ & $41(4 \%)$ & $10(1 \%)$ & $p<0.0001$ \\
$>5 \mathrm{~mm}$ & $13(1 \%)$ & $11(1 \%)$ & $2(0.2 \%)$ & $p<0.0001$ \\
Missing & $1(0.1 \%)$ & $1(0.1 \%)$ & & \\
\hline
\end{tabular}

${ }^{\mathrm{a}}$ Mean (SD); all others = number $(\%)$.

CT, computed tomography; RUBICS, Radboud University Brain Injury Cohort Study; mTBI, mild traumatic brain injury; GCS, Glasgow Coma Scale, TCDB, Trauma Coma Databank; EDH, epidural hematoma; SDH, subdural hematoma; SAH, subarachnoid hemorrhage; GOSE, Glasgow Outcome Scale-Extended.

score of 14 , and $46 \%$ of patients with a GCS score of 13 . Aside from the status of the foramen magnum and basal cisterns, the patients lost to follow-up were significantly less severely injured according to CT abnormalities, than patients for whom GOSE scores were available.

Univariate binary logistic regression analysis showed that several clinical and CT characteristics predict outcome after mTBI (Table 3). In addition we re-analyzed the predictive value of the presence of PTA and LOC, including the ambiguous scores; again the presence of PTA (odds ratio [OR] $1.0,99 \%$ confidence interval $[\mathrm{CI}] 0.7,1.5)$ and LOC (OR 0.8, $99 \%$ CI $0.5,1.2)$ were not indicative of outcome. When the univariate analysis was performed without the neurosurgical patients, the GCS (OR 0.8, 95\% CI 0.6, 1.02), and the presence of pneumocephalus (OR 2.0, 95\% CI 0.9, 4.4) lost their predictive value. Multivariate analysis of the demographic and clinical variables showed that age, ISSe, and AISH scores were predictors of unfavorable outcome, whereas day-of-injury alcohol intoxication was associated with a favorable outcome. The multivariate analysis was carried out without the neurosurgical patients as well, which did not change the results. A multivariate analysis of the possible clinical predictors and age done without the 53 patients that had an interpreted GOSE score did not change the results; only the 99\% CIs changed minimally (data not shown). These four variables were used to design the "clinical" predictive rule (Table 5). The combination of ISSe and AISH could be replaced by the total ISS score (OR 1.07, 99\% CI 1.06, 1.1). Multivariate analysis of the CT characteristics showed that the number of hemorrhagic contusions and the presence of facial fractures were outcome predictors (Table 3 ). From these characteristics the predictive "CT rule" was formulated (Table 5). The multivariate analysis of potential CT predictors was carried out sequentially, excluding the neurosurgical patients and the 53 patients mentioned above as well. Again the results did not change significantly; the OR of the number of hemorrhagic contusions slightly increased to $1.9(99 \%$ CI $1.2,3.1)$, as was true for the OR of the presence of facial fractures (OR 1.8, 99\% CI 1.2, 3.0).

Thus age, ISSe, alcohol intoxication, and the number of hemorrhagic contusions emerged as significant outcome predictors after multivariate analysis of the combined demo- graphic, clinical, and CT variables (Table 4). The third predictive rule, "combined," was designed using these predictors (Table 5C). When we reanalyzed the multivariable analysis without, successively, the neurosurgical and the interpreted GOSE, the OR of the number of hemorrhagic contusions increased from 1.9 to 2.1 (95\% CI 1.2, 3.5).

Of the patients with a head CT, $1315(66 \%)$ suffered from an isolated mTBI. Of these patients, $223(17.0 \%)$ had intracranial abnormalities. Abnormal CTs were found in 165 (24.4\%) patients in the polytrauma group. For outcome prediction 669 $(51 \%)$ isolated mTBI patients could be analyzed. Unfavorable outcomes occurred in $128(16 \%)$ patients with isolated mTBI, in contrast to the $152(36 \%)$ patients in the polytrauma group. Death occurred in $26(3 \%)$ of patients with isolated $\mathrm{mTBI}$, and in $14(3 \%)$ polytrauma patients.

In the isolated mTBI group univariate $(n=669$; results not shown), and subsequent multivariate analysis of the demographic and clinical variables showed that age (OR 1.02; 99\% CI 1.003, 1.03), AISH score (OR 1.5, 99\% CI 1.2, 2.0), and dayof-injury alcohol intoxication (OR 0.3, 99\% CI 0.2, 0.7) were predictors of outcome. When the CT parameters were analyzed, only the number of hemorrhagic contusions demonstrated independent predictive value (OR 2.4, 99\% CI 1.3,4.4). After multivariate analysis of the demographic, clinical, and CT variables, age (OR 1.02, 99\% CI 1.004, 1.03), AISH score (OR 1.5, 99\% CI 1.1,2.0), and alcohol intoxication (OR 0.3, 99\% CI $0.2,0.7)$ proved to be outcome predictors. In this analysis, AISH was not replaced by the number of hemorrhagic contusions, in contrast to the analysis of the complete mTBI group. In conformity with the models predicting outcome in the entire mTBI group, in the isolated mTBI group, again three predictive rules were designed (Table 6).

The results of the ROC analysis showed that the predictive value of both CT models was limited, with AUCs of 0.57 and 0.56 (Fig. 2 and Table 7). The "clinical" models demonstrated the highest predictive values. Combination of clinical and CT predictors, so-called combination models, did not improve the performance of the "clinical" models. In the mTBI group the rule based on clinical variables had a higher AUC than the rule based on the combination of clinical and CT parameters. This seems to contradict the rule that states that a wider choice of variables always leads to an improved model. However, it 
Table 3. Results of the Univariate and Multivariate Analyses of Clinical and CT Characteristics $(N=1069)$

\begin{tabular}{|c|c|c|c|c|}
\hline \multirow[b]{2}{*}{ Characteristic } & \multicolumn{2}{|c|}{ Univariate analysis } & \multicolumn{2}{|c|}{ Multivariate analysis } \\
\hline & OR. & $99 \% \mathrm{CI}$ & OR. & $99 \% C I$ \\
\hline \multicolumn{5}{|l|}{ Clinical } \\
\hline Gender & 1.3 & $0.9,1.8$ & & \\
\hline Age $(y)^{a}$ & 1.02 & $1.01,1.03$ & 1.02 & $1.01,1.03$ \\
\hline $\mathrm{GCS}^{\mathrm{b}}$ & 0.7 & $0.6,0.99$ & & \\
\hline Abnormal pupillary response & 1.6 & $0.4,5.8$ & & \\
\hline Hypotensive episode & 2.7 & $0.9,8.2$ & & \\
\hline Hypoxic episode & 2.2 & $0.7,6.9$ & & \\
\hline $\mathrm{AISH}^{\mathrm{b}}$ & 1.4 & $1.1,1.7$ & 1.3 & $1.1,1.7$ \\
\hline ISS $^{\mathrm{b}}$ & 1.07 & $1.05,1.09$ & & \\
\hline $\mathrm{ISSe}^{\mathrm{b}}$ & 1.06 & $1.04,1.09$ & 1.06 & $1.03,1.1$ \\
\hline Presence of PTA & 0.7 & $0.5,1.0$ & & \\
\hline Presence of LOC & 0.8 & $0.5,1.1$ & & \\
\hline Ethanol intoxication & 0.4 & $0.3,0.7$ & 0.5 & $0.3,0.8$ \\
\hline Use of anticoagulants & 1.8 & $0.8,3.8$ & & \\
\hline \multicolumn{5}{|l|}{ Computed tomography } \\
\hline Foramen magnum abnormal & 3.2 & $0.6,16.5$ & & \\
\hline Basal cisterns abnormal & 2.1 & $1.03,4.4$ & & \\
\hline No lesion & ref. & & & \\
\hline One lesion & 1.5 & $0.8,2.7$ & & \\
\hline Multiple lesions & 3.1 & $1.5,6.7$ & & \\
\hline Largest lesion & ref. & & & \\
\hline $\mathrm{EDH}$ & 1.6 & $0.6,4.4$ & & \\
\hline $\mathrm{SDH}$ & 1.6 & $0.7,4.0$ & & \\
\hline Hemorrhagic contusion & 2.2 & $1.1,4.2$ & & \\
\hline Number of EDHs per patient ${ }^{c}$ & 1.7 & $0.7,4.2$ & & \\
\hline Number of SDHs per patient ${ }^{C}$ & 2.0 & $0.9,4.1$ & & \\
\hline Number of hem. cont. p.p. ${ }^{c}$ & 1.9 & $1.1,3.6$ & 1.8 & $1.1,2.8$ \\
\hline Dominant lesion volume $(\mathrm{mL})^{\mathrm{d}}$ & 1.01 & $1.0,1.02$ & & \\
\hline Presence of petechial hemorrhage & 1.1 & $0.6,2.1$ & & \\
\hline Presence of SAH & 2.0 & $1.1,3.7$ & & \\
\hline Presence of edema & 1.8 & $1.1,2.8$ & & \\
\hline Vault fracture & 2.0 & $1.0,4.2$ & & \\
\hline Skullbase fracture & 1.4 & $0.7,2.9$ & & \\
\hline Pneumocephalus & 2.2 & $1.03,4.8$ & & \\
\hline Facial fracture & 1.8 & $1.1,2.8$ & 1.7 & $1.1,2.7$ \\
\hline Midline shift & 2.0 & $0.9,4.7$ & & \\
\hline Shift $\mathrm{mm}^{\mathrm{d}}$ & 1.1 & $1.0,1.3$ & & \\
\hline
\end{tabular}

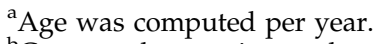

${ }^{\mathrm{b}}$ Computed per point on the scale.

'Per hematoma.

${ }^{\mathrm{d}}$ Per milliliter respectively per millimeter.

CT, computed tomography; OR, odds ratio; CI, confidence interval; GCS, Glasgow Coma Scale; AIS, Abbreviated Injury Scale; ISS, Injury Severity Scale; ISSe, Injury Severity Score-Extracranial; PTA, post-traumatic amnesia; LOC, loss of consciousness; EDH, epidural hematoma; SDH, subdural hematoma; hem. cont., hemorrhagic contusion; p.p., per patient; SAH, subarachnoid haemorrhage; ref., reference.

is a result of missing values and of the variable selection procedure, which dictated that only significant variables could be used. We therefore reran the model with less strict criteria and found that, although the AUCs increased slightly, the AUC of the model including clinical and CT characteristics never showed any significant improvement over the model using clinical variables only.

The $10 \%$ of the mTBI patients with the lowest scores (young, alcohol-intoxicated patients without extracranial injuries and no intraparenchymal contusions), when assessed with the "combination" model had a probability of an unfavorable outcome of $7.8 \%$. On the other hand, in the mTBI patients with the highest scores (elderly patients with extracranial injuries and intraparenchymal contusions, without
Table 4. Results of the Multivariate Analysis of the Combined Clinical and CT Characteristics

\begin{tabular}{lll}
\hline Characteristic & OR & $99 \% \mathrm{CI}$ \\
\hline Multivariate analysis $(n=1069)$ & & \\
Age $^{\mathrm{a}}$ & 1.02 & $(1.01,1.03)$ \\
ISSe $^{\mathrm{b}}$ & 1.07 & $(1.04,1.1)$ \\
Ethanol intoxication $_{\text {Number of hemorrhagic contusions }}$ & 0.5 & $(0.3,0.8)$ \\
Facial fracture(s) $^{\mathrm{c}}$ & 1.9 & $(1.2,3.1)$ \\
& 1.5 & $(0.9,2.5)$ \\
\hline
\end{tabular}

${ }^{\mathrm{a} A g e}$ was computed per year; ${ }^{\mathrm{b}}$ computed per point on the scale; not significant.

$\mathrm{CT}$, computed tomography; $\mathrm{OR}$, odds ratio; $\mathrm{CI}$, confidence interval; ISSe, Injury Severity Score-Extracranial; PTA, post-traumatic amnesia. 
Table 5. Rules for Predicting Unfavorable Outcome at 6 Months After mTBi $(N=1069)$

\begin{tabular}{ll}
\hline A. Clinical variables & $\mathrm{A}=-2.8+0.017^{*}$ age $+0.30^{*} \mathrm{AISH}+0.070^{*} \mathrm{ISSe}-0.80^{*}$ ethanol intoxication \\
B. CT characteristics & $\mathrm{B}=-1.3+0.58^{*}$ number of hem. contusions $+0.52^{*}$ presence of facial fracture(s) \\
C. Combined & $\mathrm{C}=-2.2+0.018^{*}$ age $+0.065^{*} \mathrm{ISSe}+0.65^{*}$ number of hem. contusions $-0.75^{*}$ ethanol intoxication
\end{tabular}

Age in years, ISSe, and AISH in points, ethanol intoxication, and presence of facial fracture(s) ( 1 present, 0 absent) are used. To calculate the probability of an unfavorable outcome the value of $\mathrm{A}, \mathrm{B}$, or $\mathrm{C}$ has to be inserted into the formula: $1 /\left(1+\mathrm{e}^{-\mathrm{A}, \mathrm{B}, \text { or } \mathrm{C}}\right)$.

mTBI, mild traumatic brain injury; CT, Computed tomography; AISH, Abbreviated Injury Scale Head score; ISSe, Injury Severity ScaleExtracranial Score; hem., hemorrhagic.

alcohol intoxication), or the lowest $10 \%$, the probability of an unfavorable outcome was $49.5 \%$.

\section{Discussion}

The main finding of this prospective cohort study is that of all demographic and acute injury characteristics studied, age, extracranial injury (as represented by the ISS or ISSe), and day-of-injury alcohol intoxication were the strongest independent predictors of functional outcome at 6 months after mTBI. The only CT characteristic that added marginally to the prediction of outcome was the number of intraparenchymal hemorrhagic contusions.

Our finding of the predictive value of age and additional extracranial injuries are in accord with other results seen in the literature (Perel et al., 2008; Signorini et al., 1999; Stulemeijer et al., 2006, 2007; Thornhill et al., 2000). Of the clinical variables, PTA (present in $61 \%$ of patients), and LOC (present in $41 \%$ of patients) did not show predictive value after univariate analysis. The percentage of our patients with LOC and/or PTA appears to be lower than that found in the literature, where LOC was present in 47.2-64.4\% (Borczuk, 1995; Smits et al., 2005; Stiell et al., 2005), and PTA was present in 69.2$73.7 \%$ (Savola and HIllbom, 2003) of mTBI patients. One explanation for this discrepancy may be that we categorized patients in whom the presence of PTA and LOC was unclear (9\% for PTA and 25\% for LOC) as not experiencing these sequelae. However, in the logistic regression analysis we analyzed the ambiguous PTA and LOC scores both included in and excluded from the "present" group, and found no significant difference. Further, we deliberately included patients without PTA and LOC, since the absence of these factors in head-injured patients does not fully rule out mTBI (Smits et al., 2007b; Viola et al., 2000).

The presence of day-of-injury alcohol intoxication was associated with favorable outcomes in our study. One explanation may be that alcohol intoxication can interfere with the initial assessment of injury severity, because it potentially affects the level of consciousness and post-acute cognitive and memory functioning (Jurkovich et al., 1992; Kelly et al., 1997; Tate et al., 1999). Hence the attending physician may over- estimate the effects of head injury in intoxicated patients, for instance due to a suboptimal GCS score (13-14), or the apparent presence of PTA as a result of diminished attention, and diagnose a mTBI when in fact the patient did not suffer any brain injury. Recent studies have shown no significant difference in short-term and long-term neuropsychological functioning between mTBI patients with and those without day-of-injury alcohol intoxication (Lange et al., 2008; Wilde et al., 2004). Nevertheless, alcohol intoxication should never lead to an underestimation of trauma severity. In intoxicated patients it may be necessary to exclude life-threatening intracranial injury first, before designating alcohol or drug use as the cause of impaired consciousness, amnesia, or behavioral disturbances (National Institute for Clinical Excellence, 2003).

The frequency of CT abnormalities in mTBI patients with hospital admission GCS scores of 13-15 seen in our study (19.5\% intracranial abnormalities, and $20.7 \%$ when skull or skullbase fractures are included) is higher than that found in several other studies: 6\% (Ibanez et al., 2004), 7.5\% (Styrke et al., 2007), 9.8\% (Smits et al., 2005), 12\% (Stiell et al., 2001), and $12.1 \%$ (Stiell et al., 2005). There are, however, studies that support our data, showing comparable or even higher frequencies of CT abnormalities: 16.9\% (Shackford et al., 1992), 17.2\% (Stein and Ross, 1992), and 25.9\% (Bordignon and Arruda, 2002). A potential reason for these discrepancies concerns the inclusion criteria of the mTBI patients. Most studies included only patients with LOC and/or PTA. Head injury without LOC and PTA, however, does not preclude the presence of intracranial abnormalities, and they may be present in $0.5-4.9 \%$ of patients (Smits et al., 2007b; Viola et al., 2000). In our study head-injured patients without LOC and PTA were included, because our hospital protocol is based on the presence of risk factors rather than loss of or impairment of consciousness, which are part of the EFNS guidelines (Vos et al., 2002). These guidelines are derived in part from the Canadian (Stiell et al., 2001) and New Orleans (Haydel et al., 2000) CT prediction rules, and therefore lead to a higher frequency of CT abnormalities. Moreover, a recent study showed that when the EFNS head-CT guideline is directly compared to other protocols, the EFNS protocol has the

Table 6. Rules for Predicting Unfavorable Outcome at 6 Months After Isolated mTBi $(N=669)$

\begin{tabular}{ll}
\hline A. Clinical variables & $\mathrm{A}=-3.1+0.017^{*}$ age $+0.43^{*} \mathrm{AISH}-1.1^{*}$ ethanol intoxication \\
B. CT characteristics & $\mathrm{B}=-1.7+0.90^{*}$ number of hem. contusions \\
C. Combined & $\mathrm{C}=-3.0+0.018^{*}$ age $+0.38^{*} \mathrm{AISH}-1.11^{*}$ ethanol intoxication
\end{tabular}

Age in years, AISH score in points, and ethanol intoxication: (1 present, 0 absent) are used. To calculate the probability of an unfavorable outcome the value of $\mathrm{A}, \mathrm{B}$, or $\mathrm{C}$ has to be inserted into the formula: $1 /\left(1+\mathrm{e}^{-\mathrm{A}, \mathrm{B}, \text { or } \mathrm{C}}\right)$.

mTBI, mild traumatic brain injury; AISH, Abbreviated Injury Scale Head score; CT, Computed tomography, hem., hemorrhagic. 

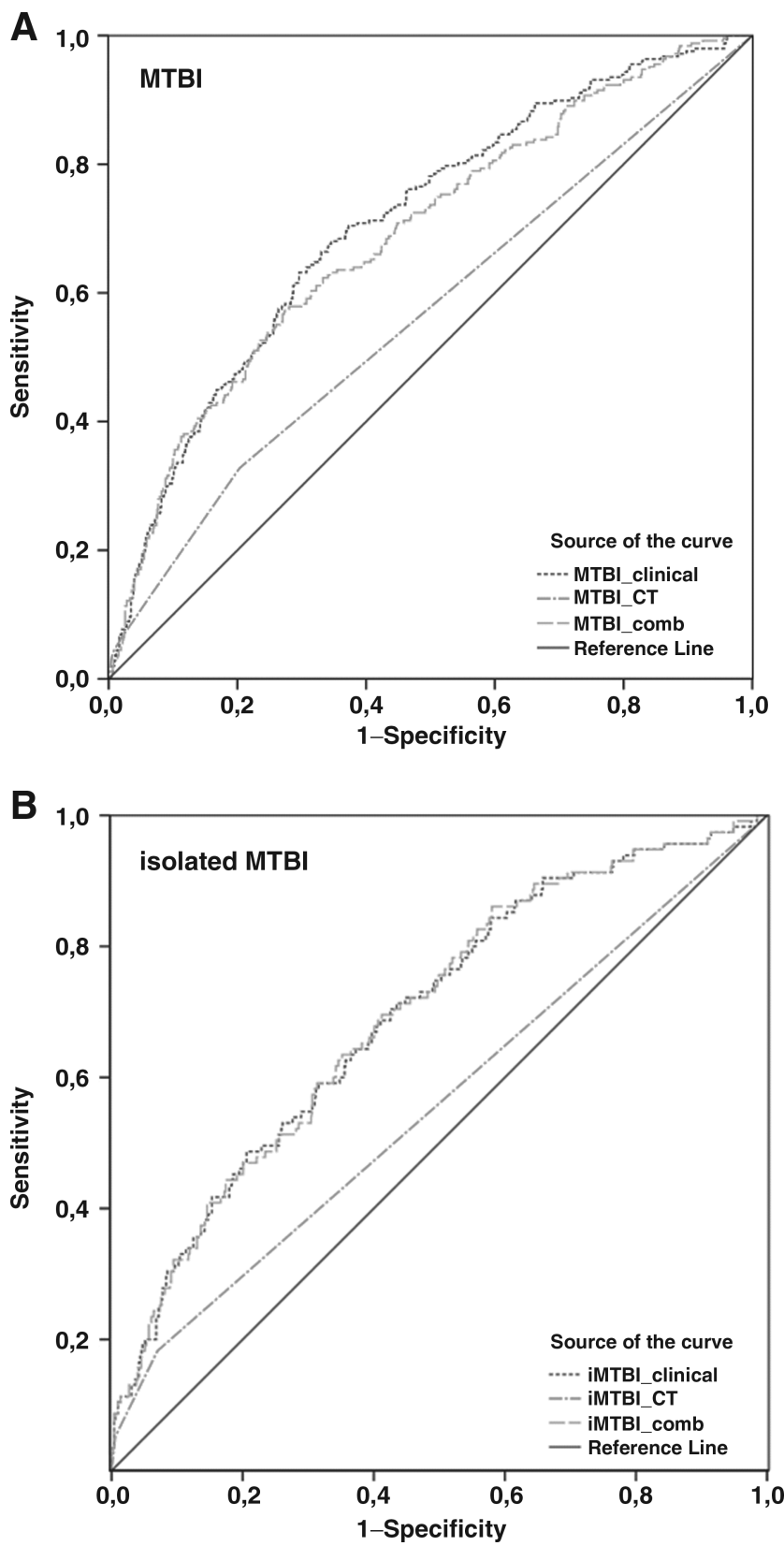

FIG. 2. (A and B) Receiver operating characteristic (ROC) curves of three prediction models in the entire mTBI group, and three analogous models in the isolated mTBI patients (mTBI, mild traumatic brain injury; imTBI, isolated mTBI; comb, combination; CT, computed tomography).

highest sensitivity in detecting intracranial abnormalities in mTBI (Smits et al., 2007a). Further, we included secondary referrals from level II and III centers, who by definition have intracranial abnormalities, and polytrauma patients with mTBI, who are more prone to having intracranial lesions than isolated head-injured patients.

In our study, several individual CT characteristics, such as the status of the basal cisterns, and the presence of SAH, edema, and pneumocephalus were associated with worse outcome after mTBI. However, after multivariate logistic regression analysis, we found only two independent CT pre-
Table 7. Area Under the Receiver Operating

Characteristic Curve (AUC) of Six Models,

Three Predicting Unfavorable Outcome IN MTBI AND THREE IN ISOLATED MTBI

\begin{tabular}{lcc}
\hline Model & AUC & CI (95\%) \\
\hline mTBI group $(n=1069)$ & & \\
Clinical variables & 0.71 & $(0.67,0.75)$ \\
CT parameters & 0.57 & $(0.52,0.61)$ \\
Clinical and CT variables combined & 0.69 & $(0.65,0.73)$ \\
Isolated mTBI group $(n=669)$ & & \\
Clinical variables & 0.69 & $(0.64,0.75)$ \\
CT parameters & 0.56 & $(0.50,0.62)$ \\
Clinical and CT variables combined & 0.70 & $(0.64,0.75)$
\end{tabular}

mTBI, mild traumatic brain injury; $\mathrm{CI}$, confidence interval; $\mathrm{CT}$, computed tomography.

dictors of outcome (the presence of facial fractures and the number of intracranial hemorrhagic contusions). The negative influence of facial fractures on post-traumatic neuropsychological and functional outcome after mTBI has been previously demonstrated (Bisson et al., 1997; Martin et al., 2002). The presence and size of hemorrhagic contusions, including traumatic intraparenchymal hemorrhages, have an adverse effect on outcome after TBI, particularly in severe TBI (Maas et al., 2007). The negative effect of hemorrhagic contusions on outcome has also been demonstrated in studies that incorporated more severely injured TBI patients (van der Naalt et al., 1999a; Wallesch et al., 2001). In contrast to severe TBI, in mTBI the size of intracranial lesions has no influence on outcome (Marshall et al., 1991).

From the independent predictors we composed three simple prediction models. The first model consisted of demographic and clinical variables, the second model of CT parameters, and the third model of combined clinical/ demographic and CT characteristics. Whereas an AUC of 0.50 equals random guessing, and an AUC of 1.0 is the best possible score, the CT model in the overall mTBI group had only limited predictive value (AUC 0.57), compared to the moderate AUC of 0.71 of the clinical model. Moreover, the CT characteristics did not add any predictive value, resulting in an AUC of 0.69 in the combined model. In isolated mTBI the AUC of the CT model (AUC 0.56; 95\% CI 0.50, 0.62) did not reach statistical significance, and the AUC of the clinical model was only moderate, at 0.69 . Of course CT remains an indispensable tool to identify patients in need of neurosurgical intervention. The presence of CT abnormalities might further delay recovery and influence short-term outcome, but the value of CT appears to be limited for the prediction of long-term outcome in mTBI patients.

The importance of these findings is that contrary to intuitive beliefs, and unlike those with moderate to severe TBI, CT, demographic, and clinical characteristics are only modest predictors of outcome after mTBI. One reason for these findings may be that for prediction of outcome post-mTBI, factors other than age, clinical, and CT characteristics should be considered. Pre-existing physical comorbidities, severe postconcussion symptoms, and post-traumatic stress immediately after mTBI appear to affect the number or patients with postconcussional symptoms 6 months or more after mTBI (Stu- 
lemeijer et al., 2007). Further, the number of years of formal education, the presence of nausea or vomiting on ED admission, concurrently sustained extracranial injuries, and the pain levels seen early after injury, all appear to affect time to return to work after mTBI (Stulemeijer et al., 2007). A survey of U.S. Army infantry soldiers done after their return from Iraq demonstrated that post-traumatic stress disorder and depression are mediators of the relationship between mTBI and physical health problems more than 3 months post-injury (Hoge et al., 2008). None of these factors, apart from additional extracranial injury, were included in the current study. We also did not investigate the roles of other potential predictors of outcome, including genetic polymorphisms and biomarkers of brain damage. Future predictive models might have stronger predictive power if these variables were added.

\section{Limitations}

This study has some limitations. First, only mTBI patients requiring neurological or neurosurgical consultation at the ED were included. Therefore patients seen only by the ED physician were not included, which may have caused inclusion bias. According to our hospital protocol, patients experiencing head injury without LOC or PTA, a GCS score of 15 or more, and no risk factors (i.e., not fulfilling the EFNS criteria described above) (Vos et al., 2002), were not included. This category of patients, with slight head injury without mTBI, has an extremely low risk of having intracranial abnormalities, and thus they would contribute little to our predictive model. Moreover, these patients were excluded from most of the studies cited above, and they do not fulfill the criteria for mTBI as defined by the mTBI Committee of the Head Injury Interdisciplinary Special Interest Group of the American Congress of Rehabilitation Medicine (Kay et al., 1993).

Additionally, patient follow-up was of concern despite the prospective design of the study. In the CT-only group $46 \%$ patients were lost to follow-up, making extrapolation to our entire population more difficult. The low follow-up rate was partly caused by high rates of patients with alcohol and drug abuse problems, psychiatric patients, and homeless persons. A number of foreigners, who were visiting and thus unavailable for follow-up consultations, was also included. Furthermore, we suspect that mTBI patients with few complaints or symptoms are unlikely to visit the outpatient clinic. The high rate of loss to follow-up and the bias that may result has been described previously by others (Corrigan et al., 2003). Generalizability may also be limited by the fact that the patients included in the outcome analysis had a more severe injury profile, as demonstrated by GCS, AISH, and ISS scores, and CT characteristics. Our models may therefore have the most value for more severely injured mTBI patients, especially those that undergo a head CT scan. For less severely injured mTBI patients, a different type of prognostic model may yield better results.

Third, although the patients were prospectively selected and included in the RUBICS database, the clinical data were collected from the patient charts by a research nurse, and many of the CT scans were reviewed within $24 \mathrm{~h}$ post-injury. This may have given our study a partly retrospective nature, and may have led to missing data. The additional follow-up was nonetheless prospectively performed. A small proportion of the GOSE scores $(n=53,5.0 \%)$ were derived from patient charts using accessory queries that were previously formulated (Wilson et al., 1998). When these questions could not be answered adequately using the available data, the patient was regarded as lost to follow-up. We therefore think it unlikely that invalid GOSE scores were used in this study. Nevertheless, we reran the various multivariate analyses without these 53 patients, and only minimal changes in the ORs and CIs were found. Thus we based the final prediction models on the results from the multivariate analyses performed on all 1069 patients.

Finally, no external validation has been performed. The prediction models should be validated by a separate cohort study to determine its generalizability.

\section{Conclusion and future research}

Our study shows that age and extracranial injuries (high ISSe scores) are the strongest predictors of unfavorable outcome in mTBI, and they are stronger than admission CT characteristics. Further, the presence of day-of-injury alcohol intoxication is associated with favorable outcomes after mTBI, probably due to its interference with the initial assessment of injury severity. We propose a simple prediction model using these factors, and we believe that future prognostic models for mTBI should include these variables. To ensure its applicability, the validity of this prediction model is essential, and thus an external validation study is necessary.

\section{Acknowledgments}

We would like to thank Jolanda Brauer and Else Eleveld for the data collection and registration.

\section{Author Disclosure Statement}

No competing financial interests exist.

\section{References}

af Geijerstam, J.L., and Britton, M. (2003). Mild head injurymortality and complication rate: meta-analysis of findings in a systematic literature review. Acta Neurochir. (Wien.) 145, 843850.

af Geijerstam, J.L., and Britton, M. (2005). Mild head injury: reliability of early computed tomographic findings in triage for admission. Emerg. Med. J. 22, 103-107.

af Geijerstam, J.L., Oredsson, S., and Britton, M. (2006). Medical outcome after immediate computed tomography or admission for observation in patients with mild head injury: randomised controlled trial. BMJ 333, 465, Epub 2006 Aug 8.

American College of Surgeons. (2004). Shock, in: Advanced Trauma Life Support for Doctors. ACS: Chicago, pps. 69-102.

Baker, S.P., O'Neill, B., Haddon, W., Jr., and Long, W.B. (1974). The injury severity score: a method for describing patients with multiple injuries and evaluating emergency care. J. Trauma 14, 187-196.

Bisson, J.I., Shepherd, J.P., and Dhutia, M. (1997). Psychological sequelae of facial trauma. J. Trauma 43, 496-500.

Borczuk, P. (1995). Predictors of intracranial injury in patients with mild head trauma. Ann. Emerg. Med. 25, 731-736. 
Bordignon, K.C., and Arruda, W.O. (2002). CT scan findings in mild head trauma: a series of 2,000 patients. Arq. Neuropsiquiatr. 60, 204-210.

Carroll, L.J., Cassidy, J.D., Peloso, P.M., Borg, J., von Holst, H., Holm, L, Paniak, C., and Pépin, M. (2004). Prognosis for mild traumatic brain injury: results of the WHO Collaborating Centre Task Force on Mild Traumatic Brain Injury. J. Rehabil. Med. Suppl. 43, 84-105.

Cassidy, J.D., Carroll, L.J., Peloso, P.M., Borg, J., von Holst, H., Holm, L., Kraus, J., and Coronado, V.G. (2004). Incidence, risk factors and prevention of mild traumatic brain injury: results of the WHO Collaborating Centre Task Force on Mild Traumatic Brain Injury. J. Rehabil. Med. Suppl. 43, 28-60.

Chamelian, L., and Feinstein, A. (2004). Outcome after mild to moderate traumatic brain injury: the role of dizziness. Arch. Phys. Med. Rehabil. 85, 1662-1666.

Corrigan, J.D., Harrison-Felix, C., Bogner, J., Dijkers, M., Terrill, M.S., and Whiteneck, G. (2003). Systematic bias in traumatic brain injury outcome studies because of loss to follow-up. Arch. Phys. Med. Rehabil. 84, 153-160.

Culotta, V.P., Sementilli, M.E., Gerold, K., and Watts, C.C. (1996). Clinicopathological heterogeneity in the classification of mild head injury. Neurosurgery 38, 245-250.

de Andrade, A.F., de Almeida, A.N., Bor-Seng-Shu, E., Lourenco, L., Mandel, M., and Marino, R., Jr. (2006). The value of cranial computed tomography in high-risk, mildly headinjured patients. Surg. Neurol. 65(Suppl. 1), S10-S13.

de Kruijk, J.R., Leffers, P., Menheere, P.P., Meerhoff, S., Rutten, J., and Twijnstra, A. (2002). Prediction of post-traumatic complaints after mild traumatic brain injury: early symptoms and biochemical markers. J. Neurol. Neurosurg. Psychiatry 73, 727-732.

Dunham, C.M., Coates, S., and Cooper, C. (1996). Compelling evidence for discretionary brain computed tomographic imaging in those patients with mild cognitive impairment after blunt trauma. J. Trauma 41, 679-686.

Gomez, P.A., Lobato, R.D., Ortega, J.M., and De La Cruz, J. (1996). Mild head injury: differences in prognosis among patients with a Glasgow Coma Scale score of 13 to 15 and analysis of factors associated with abnormal CT findings. Br. J. Neurosurg. 10, 453-460.

Harad, F.T. and Kerstein, M.D. (1992). Inadequacy of bedside clinical indicators in identifying significant intracranial injury in trauma patients. J. Trauma 32, 359-361.

Haydel, M.J., Preston, C.A., Mills, T.J., Luber, S., Blaudeau, E., and DeBlieux, P.M. (2000). Indications for computed tomography in patients with minor head injury. N. Engl. J. Med. 343, 100-105.

Hoge, C.W., McGurk, D., Thomas, J.L., Cox, A.L., Engel, C.C., and Castro, C.A. (2008). Mild traumatic brain injury in U.S. soldiers returning from Iraq. N. Engl. J. Med. 358, 453-463.

Hsiang, J.N., Yeung, T., Yu, A.L., and Poon, W.S. (1997). Highrisk mild head injury. J. Neurosurg. 87, 234-238.

Hukkelhoven, C.W., Steyerberg, E.W., Habbema, J.D., Farace, E., Marmarou, A., Murray, G.D., Marshall, L.F., and Maas, A.I. (2005). Predicting outcome after traumatic brain injury: development and validation of a prognostic score based on admission characteristics. J. Neurotrauma 22, 1025-1039.

Ibanez, J., Arikan, F., Pedraza, S., Sanchez, E., Poca, M.A., Rodriguez, D., and Rubio, E. (2004). Reliability of clinical guidelines in the detection of patients at risk following mild head injury: results of a prospective study. J. Neurosurg. 100, 825-834.
Ingebrigtsen, T., Romner, B., and Kock-Jensen, C. (2000). Scandinavian guidelines for initial management of minimal, mild, and moderate head injuries. The Scandinavian Neurotrauma Committee. J. Trauma 48, 760-766.

Iverson, G.L., Lovell, M.R., Smith, S., and Franzen, M.D. (2000). Prevalence of abnormal CT-scans following mild head injury. Brain Inj. 14, 1057-1061.

Jeret, J.S., Mandell, M., Anziska, B., Lipitz, M., Vilceus, A.P., Ware, J.A., and Zesiewicz, T.A. (1993). Clinical predictors of abnormality disclosed by computed tomography after mild head trauma. Neurosurgery 32, 9-15.

Jurkovich, G.J., Rivara, F.P., Gurney, J.G., Seguin, D., Fligner, C.L., and Copass, M. (1992). Effects of alcohol intoxication on the initial assessment of trauma patients. Ann. Emerg. Med. 21, 704-708.

Kay, T., Harrington, D.E., Adams, R., Anderson, T., Berrol, S., Cicerone, K., Dahlberg, C., Gerber, D., Goka, R., Harley, P., Hilt, J., Horn, L., Lehmkuhl, D., and Malec, J. (1993). Definition of mild traumatic brain injury. J. Head Trauma Rehabil. 8, 86-87.

Kelly, M.P., Johnson, C.T., Knoller, N., Drubach, D.A., and Winslow, M.M. (1997). Substance abuse, traumatic brain injury and neuropsychological outcome. Brain Inj. 11, 391-402.

Kido, D.K., Cox, C., Hamill, R.W., Rothenberg, B.M., and Woolf, P.D. (1992). Traumatic brain injuries: predictive usefulness of CT. Radiology 182, 777-781.

Lange, R.T., Iverson, G.L., and Franzen, M.D. (2008). Effects of day-of-injury alcohol intoxication on neuropsychological outcome in the acute recovery period following traumatic brain injury. Arch. Clin. Neuropsychol. 23, 809-822.

Livingston, D.H., Lavery, R.F., Passannante, M.R., Skurnick, J.H., Baker, S., Fabian, T.C., Fry, D.E., and Malangoni, M.A. (2000). Emergency department discharge of patients with a negative cranial computed tomography scan after minimal head injury. Ann. Surg. 232, 126-132.

Maas, A.I., Steyerberg, E.W., Butcher, I., Dammers, R., Lu, J., Marmarou, A., Mushkudiani, N.A., McHugh, G.S., and Murray, G.D. (2007). Prognostic value of computerized tomography scan characteristics in traumatic brain injury: results from the IMPACT study. J. Neurotrauma 24, 303-314.

Marshall, L.F., Eisenberg, H.M., Jane, J.A., Luerssen, T.G., Marmarou, A., and Foulkes, M.A., (1991). A new classification of head injury based on computerized tomography. J. Neurosurg. 75, s14-s20.

Martin, R.C., Spain, D.A., and Richardson, J.D. (2002). Do facial fractures protect the brain or are they a marker for severe head injury? Am. Surg. 68, 477-481.

McCullagh, S., Oucherlony, D., Protzner, A., Blair, N., and Feinstein, A. (2001). Prediction of neuropsychiatric outcome following mild trauma brain injury: an examination of the Glasgow Coma Scale. Brain Inj. 15, 489-497.

Miller, E.C., Derlet, R.W., and Kinser, D. (1996). Minor head trauma: Is computed tomography always necessary? Ann. Emerg. Med. 27, 290-294.

Miller, E.C., Holmes, J.F., and Derlet, R.W. (1997). Utilizing clinical factors to reduce head CT scan ordering for minor head trauma patients. J. Emerg. Med. 15, 453-457.

Moran, S.G., McCarthy, M.C., Uddin, D.E., and Poelstra, R.J. (1994). Predictors of positive CT scans in the trauma patient with minor head injury. Am. Surg. 60, 533-535.

Nagy, K.K., Joseph, K.T., Krosner, S.M., Roberts, R.R., Leslie, C.L., Dufty, K., Smith, R.F., and Barrett, J. (1999). The utility of 
head computed tomography after minimal head injury. J. Trauma 46, 268-270.

National Institute for Clinical Excellence. (2003). Head Injury in Infants, Children and Adults: Triage, Assessment, Investigation and Early Management. http://www.nice.org.uk/ CG56.

Pasqualin, A., Barone, G., Cioffi, F., Rosta, L., Scienza, R., and Da Pian, R. (1991). The relevance of anatomic and hemodynamic factors to a classification of cerebral arteriovenous malformations. Neurosurgery 28, 370-379.

Perel, P., Arango, M., Clayton, T., Edwards, P., Komolafe, E., Poccock, S., Roberts, I., Shakur, H., Steyerberg, E., and Yutthakasemsunt, S. (2008). Predicting outcome after traumatic brain injury: practical prognostic models based on large cohort of international patients. BMJ 336, 425-429.

Ponsford, J., Willmott, C., Rothwell, A., Cameron, P., Kelly, A.M., Nelms, R., Curan, C., and Ng, K.T. (2000). Factors influencing outcome following mild traumatic brain injury in adults. J. Int. Neuropsychol. Soc. 6, 568-579.

Sadowski-Cron, C., Schneider, J., Senn, P., Radanov, B.P., Ballinari, P., and Zimmermann, H. (2006). Patients with mild traumatic brain injury: immediate and long-term outcome compared to intra-cranial injuries on CT scan. Brain Inj. 20, 1131-1137.

Savola, O., and Hillbom, M. (2003). Early predictors of postconcussion symptoms in patients with mild head injury. Eur. J. Neurol. 10, 175-181.

Servadei, F., Teasdale, G., and Merry, G. (2001). Defining acute mild head injury in adults: a proposal based on prognostic factors, diagnosis, and management. J. Neurotrauma 18, 657664.

Shackford, S.R., Wald, S.L., Ross, S.E., Cogbill, T.H., Hoyt, D.B., Morris, J.A., Mucha, P.A., Pachter, H.L., and Sugerman, H.J. (1992). The clinical utility of computed tomographic scanning and neurologic examination in the management of patients with minor head injuries. J. Trauma 33, 385-394.

Signorini, D.F., Andrews, P.J., Jones, P.A., Wardlaw, J.M., and Miller, J.D. (1999). Predicting survival using simple clinical variables: a case study in traumatic brain injury. J. Neurol. Neurosurg Psychiatry 66, 20-25.

Smits, M., Dippel, D.W., de Haan, G.G., Dekker, H.M., Vos, P.E., Kool, D.R., Nederkoorn, P.J., Hofman, P.A., Twijnstra, A., Tanghe, H.L., and Hunink, M.G. (2005). External validation of the Canadian CT Head Rule and the New Orleans Criteria for CT scanning in patients with minor head injury. JAMA 294, 1519-1525.

Smits, M., Dippel, D.W., Steyerberg, E.W., de Haan, G.G., Dekker, H.M., Vos, P.E., Kool, D.R., Nederkoorn, P.J., Hofman, P.A., Twijnstra, A., Tanghe, H.J., and Hunink, M.G. (2007a). Predicting intracranial traumatic findings on computed tomography in patients with minor head injury: the CHIP prediction rule. Ann. Intern. Med. 146, 397405.

Smits, M., Hunink, M.G., Nederkoorn, P.J., Dekker, H.M., Vos, P.E., Kool, D.R., Hofman, P.A., Twijnstra, A., de Haan, G.G., Tanghe, H.L., and Dippel, D.W. (2007b). A history of loss of consciousness or post-traumatic amnesia in minor head injury: "conditio sine qua non" or one of the risk factors? J. Neurol. Neurosurg. Psychiatry. 78, 1359-1364.

Smits, M., Hunink, M.G., van Rijssel, D.A., Dekker, H.M., Vos, P.E., Kool, D.R., Nederkoorn, P.J., Hofman, P.A., Twijnstra, A., Tanghe, H.L., and Dippel, D.W. (2008). Outcome after complicated minor head injury. AJNR Am. J. Neuroradiol. 29, 506-513.

Stein, S.C., and Ross, S.E. (1992). Mild head injury: a plea for routine early CT scanning. J. Trauma 33, 11-13.

Stein, S.C., and Ross, S.E. (1990). The value of computed tomographic scans in patients with low-risk head injuries. Neurosurgery 26, 638-640.

Stiell, I.G., Clement, C.M., Rowe, B.H., Schull, M.J., Brison, R., Cass, D., Eisenhauer, M.A., McKnight, R.D., Bandiera, G., Holroyd, B., Lee, J.S., Dreyer, J., Worthington, J.R., Reardon, M., Greenberg, G., Lesiuk, H., MacPhail, I., and Wells, G.A. (2005). Comparison of the Canadian CT Head Rule and the New Orleans Criteria in patients with minor head injury. JAMA 294, 1511-1518.

Stiell, I.G., Wells, G.A., Vandemheen, K., Clement, C., Lesiuk, H., Laupacis, A., McKnight, R.D., Verbeek, R., Brison, R., Cass, D., Eisenhauer, M.A., Greenberg, G.H., and Worthington, J. (2001). The Canadian CT Head Rule for patients with minor head injury. Lancet 357, 1391-1396.

Stulemeijer, M., van der Werf, S.P., Borm, G.F., and Vos, P.E. (2007). Early prediction of favorable recovery six-months after mild traumatic brain injury. J Neurol. Neurosurg. Psychiatry 79, 936-942.

Stulemeijer, M., van der Werf, S.P., Jacobs, B., Biert, J., van Vugt, A.B., Brauer, J.M., and Vos, P.E. (2006). Impact of additional extracranial injuries on outcome after mild traumatic brain injury. J. Neurotrauma 23, 1561-1569.

Styrke, J., Stalnacke, B.M., Sojka, P., and Bjornstig, U. (2007). Traumatic brain injuries in a well-defined population: epidemiological aspects and severity. J. Neurotrauma 24, 14251436.

Tate, P.S., Freed, D.M., Bombardier, C.H., Harter, S.L., and Brinkman, S. (1999). Traumatic brain injury: influence of blood alcohol level on post-acute cognitive function. Brain Inj. 13, 767-784.

Thiruppathy, S.P., and Muthukumar, N. (2004). Mild head injury: revisited. Acta Neurochir. (Wien.) 146, 1075-1082.

Thornhill, S., Teasdale, G.M., Murray, G.D., McEwen, J., Roy, C.W., and Penny, K.I. (2000). Disability in young people and adults one year after head injury: prospective cohort study. BMJ 320, 1631-1635.

van der Naalt, J., Hew, J.M., van Zomeren, A.H., Sluiter, W.J., and Minderhoud, J.M. (1999a). Computed tomography and magnetic resonance imaging in mild to moderate head injury: early and late imaging related to outcome. Ann. Neurol. 46, 70-78.

van der Naalt, J. (2001). Prediction of outcome in mild to moderate head injury: a review. J. Clin. Exp. Neuropsychol. 23, 837-851.

van der Naalt, J., van Zomeren, A.H., Sluiter, W.J., and Minderhoud, J.M. (1999b). One year outcome in mild to moderate head injury: the predictive value of acute injury characteristics related to complaints and return to work. J. Neurol. Neurosurg. Psychiatry 66, 207-213.

Viola, L., Zotta, D., Martino, V., Barbato, R., and Schisano, G. (2000). Minor head injuries: one year experience according to the new Italian guideline. Acta Neurochir. (Wien.) 142, 12811285.

Vos, P.E., Battistin, L., Birbamer, G., Gerstenbrand, F., Potapov, A., Prevec, T., Stephan, Ch.A., Traubner, P., Twijnstra, A., Vecsei, L., and von Wild, K. (2002). EFNS guideline on mild traumatic brain injury: report of an EFNS task force. Eur. J. Neurol. 9, 207-219. 
Vos, P.E., van Voskuilen, A.C., Beems, T., Krabbe, P.F., and Vogels, O.J. (2001). Evaluation of the Traumatic Coma Data Bank computed tomography classification for severe head injury. J. Neurotrauma 18, 649-655.

Wallesch, C.W., Curio, N., Kutz, S., Jost, S., Bartels, C., and Synowitz, H. (2001). Outcome after mild-to-moderate blunt head injury: effects of focal lesions and diffuse axonal injury. Brain Inj. 15, 401-412.

Wardlaw, J.M., Easton, V.J., and Statham, P. (2002). Which CT features help predict outcome after head injury? J. Neurol. Neurosurg. Psychiatry 72, 188-192.

Wilde, E.A., Bigler, E.D., Gandhi, P.V., Lowry, C.M., Blatter, D.D., Brooks, J., and Ryser, D.K. (2004). Alcohol abuse and traumatic brain injury: quantitative magnetic resonance imaging and neuropsychological outcome. J. Neurotrauma 21, 137-147.
Wilson, J.T., Edwards, P., Fiddes, H., Stewart, E., and Teasdale, G.M. (2002). Reliability of postal questionnaires for the Glasgow Outcome Scale. J. Neurotrauma 19, 999-1005.

Wilson, J.T., Pettigrew, L.E., and Teasdale, G.M. (1998). Structured interviews for the Glasgow Outcome Scale and the extended Glasgow Outcome Scale: guidelines for their use. J. Neurotrauma 15, 573-585.

Address correspondence to: Pieter E. Vos, M.D., Ph.D. Radboud University Nijmegen Medical Centre

Department of Neurology (935)

P.O. Box 9101

6500 HB Nijmegen, The Netherlands

E-mail: p.vos@neuro.umcn.nl 